\title{
Educational Model Innovating and Capability Improving Mechanism of Engineering Education Based on CDIO
}

\author{
Xiangyi Lin, Hongyun Luo, Hao Wu, Yanling Xiao \\ School of Economics and Management, Northeast Petroleum University, Daqing, China \\ Email: xlin@nepu.edu.cn
}

Received 2012

\begin{abstract}
Educational model innovating and capability improving of engineering education is the driving source of cultivating engineering talents. Combining with educational ideas and educational cycles of CDIO model, a new educational model is constructed for engineering education. The operating process of the new educational model is demonstrated according to objective conceiving, planning and designing, implementing and feedback loop. Finally, in the view of practical optimization, cross integration, moral integrity and according to redundant, the mechanism of educational capability improving is analyzed in detail.
\end{abstract}

Keywords: CDIO Model; Engineering Education; Model Innovating; Capability Improving Mechanism

\section{Introduction}

With the rapid development of global economy, the competitions between countries are not only talents, but also reserve of talents. Engineering science, supporting all industries, can maintain and promote economic stability and development. The development of engineering education plays an important role in promoting comprehensive national strength. Scientific innovation results in great changes of industrial structure. Engineering education must anticipate and adapt to this variation. In future, engineer's role will transform from working for lower technological engineering to knowledge based service economy [1]. This transformation involves in changes of knowledge system and learning pattern. Engineering education system and model is lagging behind updating speed of knowledge because of explosive expansion of knowledge system, rapid speed of knowledge updating, unprecedented broaden channels of knowledge acquisition[2]. In order to cultivate engineering talents who can adapt to the changing environment, the emphasis of engineering education should be turned into the cultivation of the students' practical ability and the adapting capability.

All of these mentioned above require establishing a new cultivating model and capability improving system for engineering education. In the past, engineering system mainly aims at industry, market and resource. Meanwhile, the cultivating direction is very single. Under the trend of globalization, the engineering education needs from angles of the world market, the world resources and a global industrial system or industrial structure to cultivate engineering talents. Due to the more and more closer international cooperation, in order to adapt to the international engineering environment, it is necessary to open up international training approaches and model of engineering education.

The model innovating and capability improving of engineering education is an important approach to cultivate international engineering talents. CDIO (Conception, Design, Implementation, Operation) model is a comprehensive international engineering talents training mode, including team cooperation and communication, individual professional skills, critical and creative thinking. The CDIO model has been the core module in the world universities' curriculums in recent years [3].

\section{Engineering Education \& CDIO}

Engineering education can cultivate engineers' talents who can establish engineering project with outstanding comprehensive capability [4]. While the current engineering education model whose academic tendency is heavy, is lack of system planning, constantly cutting the technical and practical contents and adding academic and theoretical contents in the curriculum.

CDIO model makes up for the lack of engineering education through the clear system structure and the efficient educational method. CDIO is a cycle from research to operation of the products which is made by four basic links of conception, design, implementation and operation. Each link of engineering education can be joined up, so that the students can use independent, practical and associated methods to learn engineering sciences. CDIO model puts emphasis on training high quality comprehensive engineering talents. The students should master the knowledge in technology, pay attention to reasoning ability, strengthen their own professional skills and professional ethics, and build team collaboration and interpersonal communication skills [4]. CDIO engineering ability training is a gradual process, using the strict ability training and management method to gradually improve the students' engineering ability through the continuous deliberate practice [5].

\section{Model Innovating of Engineering Education Based on the CDIO Model}

Engineering education innovation emphasizes the cultivation of both the students' theoretical knowledge and practical ability. Selecting system engineering as the whole material can reflect the practical applicability of engineering education innovation. Fitting the training philosophy of CDIO, the scientificity of introducing this model into the engineering education model innovation is demonstrated clearly by the different effects in 
each phase of the project. We can complete the whole process of the project combined with CDIO model, according to four basic steps of conceiving target, designing solution, putting into operation, realizing summary. A specific pattern is shown in Figure 1.

\section{Reasonable Set Goals}

Setting project targets can decide the development direction of the project. Therefore, how to select target is the first problem to solve for engineering education innovation. Conception is a thinking activity that presents systematic, central, hierarchical and physical integrity. Conception is an activity that builds on the past and prepares for the future; innovative conception plays an important role in final results.
CDIO model pays emphasis on transforming the education model that takes test for the purpose, and conceives an engineering education model which sets digestion and innovation as guiding direction to replace the past memory patterns. This model make higher engineering education model focus on global strategic competition, stimulate the students' subjective initiative, so that students can establish a system target on the basis of profound understanding of grasping essential attribute and movement rules of the objects. This model also can broaden students' vision outside the theoretical concept and spread their thought, take use of examples to demonstrate the international engineering project, help them analogy out their own insights and make corresponding standards for the achievement of the system targets, and then define the concept and structure to ensure the feasibility of target.

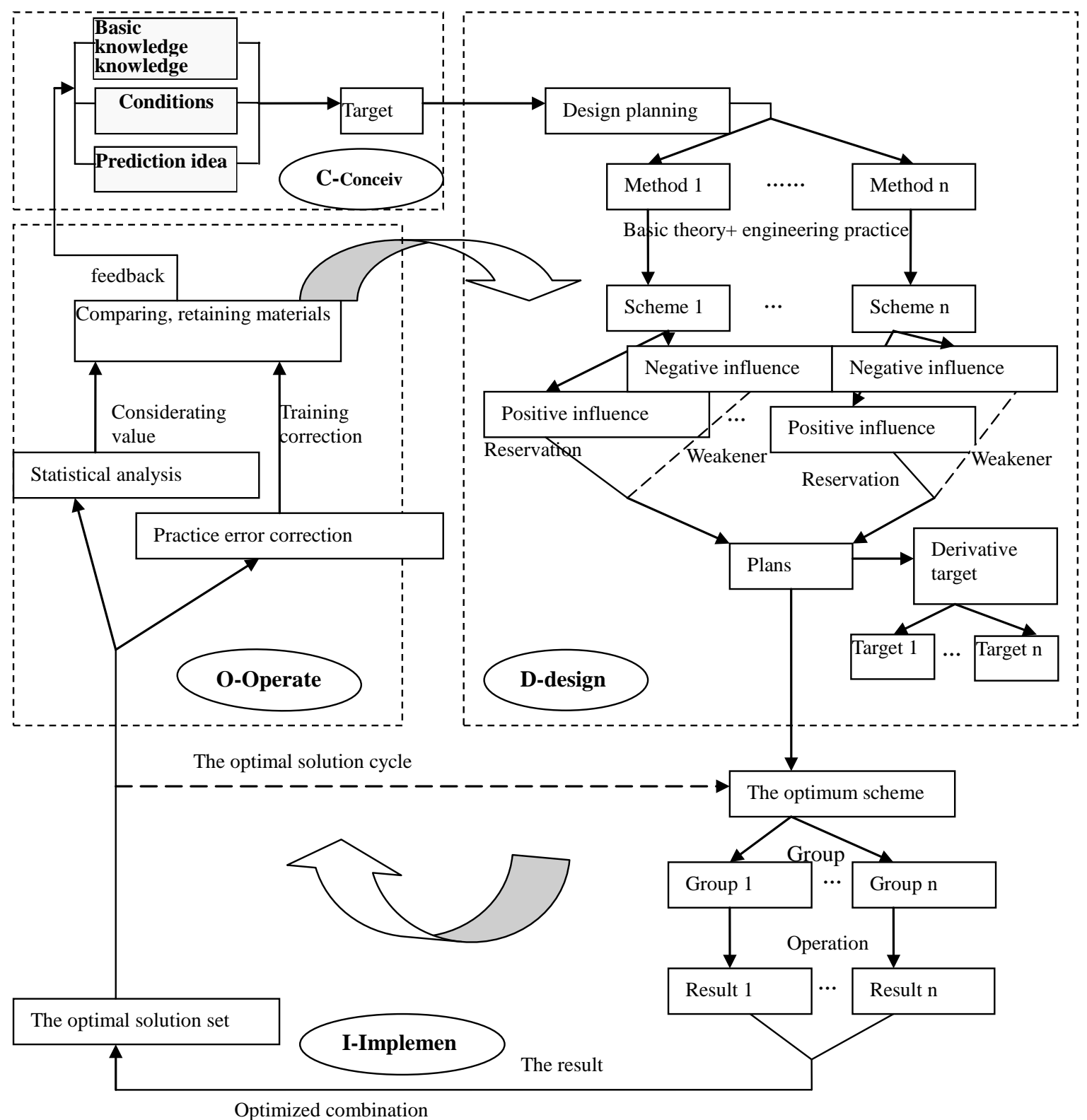

Figure 1.

Innovation Model of Engineering Education Based on CDIO model. 


\section{Design Effective Planning}

Planning is the final preparation for the project before it starts, which can not be immediately changed with project changes after it launched. Previous design planning is single and lack of diversity and innovation. However, CDIO model carries out planning innovation in accordance with the system model and standards strictly, under the premise of understanding the conception targets accurately and thoroughly. It is the continuation of the conception, and can make the planning, programming and conception outside through the visual form. It makes the previous theory or practical design approach integrated by choosing different design method and putting design scheme into subsection processing. In view of theory and practice two channels, it can reduce the possibly negative effects of system to minimum and keep the corresponding beneficial effect after operation test and theoretical calculation. When necessary, we can transform these positive factors into derivative targets and upgrade single target system to Multi- target system on the basis of the previous targets to achieve the geometry of the earnings growth.

\section{Integrate Implementing Process}

Implementation is the process that makes the conception target and design planning come true. Implementation requires data operation integration for conception target and design planning, so as to achieve the optimal expected results. The previous implementation which simply completes the task and presents the results is lack of multidimensional thinking and the comparison of results. However, CDIO model considers elements in detail involved in the process comprehensively in the software and hardware.

CDIO model no longer sets the simulation project or manufacturing plant as the main practice site. It Contacts with the enterprises related to the program and contracts the fast and exploratory engineering tasks. Let the students do engineering work in different groups according to their characteristics, so that the same goal could bring out a variety of results.

Drawing up the measure standard after the end of the project practice, the corresponding course teachers should make adjustment for every link in order to reflect the specific process more accurately and draw up the measure standards of performance [6]. This model no longer selects preferred scheme, but keeps excellent part of the process, and then integrates the summarized data materials to carry out the best scheme through the discussion audit. Excellent students should be selected in each process of the project according to the optimal solutions of the target. The teachers should redistribute the groups and carry the optimal solution back to the original projects to integrate the software and hardware, and operates the cycle once again. The cycle times can be chosen according to the requirements of project. The project can be constantly upgraded by the above test, confirmation, verification and authentication.

\section{Optimization of Feedback Loop}

Feedback loop is the last stage of the whole engineering project. The purpose of this stage is looking for the shortcomings and shortages of the system and making a summary of excellent feedback in order to make sufficient preparation for next system cycle.

The summary of system only remained on statistics and re- sults analysis in the past, which can't always achieve the effectiveness of practical application. CDIO mode, is not only statistics and results analysis, but also continues to simulate error correction, repeat training operation on outstanding shortages of every step. Improving system process can support life cycles of engineering project system preferably. Adding with new design goal can lead optimization evolvement of engineering project system. Considering the dominant and recessive value comprehensively, feedback the details of fewer value and guaranteeing the nature of high value of engineering project, all of these above can be reference material for next system cycle.

\section{Capability Improving Mechanism of CDIO Engineering Education}

The improvement of engineering education capability is the security of better engineering talents' output. The engineering education under the CDIO mode has better applicability, diversity and innovation of educational methods, and pays more attention on the practicable education, composite subjects' education and humanistic quality outside classroom. Therefore, according to the teaching features of the CDIO mode, in order to improve the quality and effect of the engineering education, the following mechanisms should be followed.

\section{Practice Optimization Mechanism}

The engineering education under CDIO mode is a process that recombining the four basic stages of CDIO mode and actually operating with the continually updating knowledge. The purpose of modern engineering education is cultivating the prototype of the modern engineers from professional natures. However, the current engineering graduates mostly can't satisfy the enterprises' demands of high skilled degrees. On one hand, criticisms on education have shown ignoring the practice in the training; on the other hand, excessively attention paid to the students' practical training may cause students' shortage of knowledge. By subdividing and optimizing the specialization of practice, balancing the relationship between theory knowledge and practice operation, the engineering education can be developed towards more systematic direction, such as "large scale engineering”, “micro scale engineering”, etc. Modern engineering usually has the close relation with scientific and technological innovation, economic development and social progress. So engineering education is no longer the "professional" education as known before, but a process of knowing more widely outside the world through continuous learning and practice, which still has the character of engineering [7]. Based on the cognition of new changes of engineering, better understanding the practical optimization can promote the engineering education capability.

\section{Ccross and Iintegration Mechanism}

With the development of the society, the complexity and diversity of the problem in engineering field is increasing. It is difficult to answer and explain engineering problem only by scientific engineering knowledge, so it is necessary to use scientific knowledge of other fields to conduct research on engineering problem in-depth. As students of this age lacking of practice knowledge in related fields, such as industrial materials, mechanical design, life cycle, and so engineering education should set up multi-discipline courses in different 
fields, which can expand the vision of students. Building real working environment can give students opportunities to manage and participate in the link of engineering project themselves like researching, manufacturing and detection. The whole operation of a project system can help students promote cognitive degree of different scientific fields, which can cultivate interdisciplinary talents for engineering.

\section{Iintegration Mechanism of Capability and Political Integrity}

The talents who are trained under CDIO engineering education model should have not only strong understanding and innovative capability, but also noble ethics. It is not only related to the development of the engineering education itself, but also has impact on the whole society environment. Individual moral, social role and responsibility consciousness will affect the engineers' ethics. Facing the increasingly complex social environment and the interest relations, the cultivation of engineers' personnel ethics and morals has become an arduous task in engineering education. Because engineering ethics are influenced by engineering effectiveness, social culture and natural environment restriction[8], CDIO engineering education model puts always emphasizes on the unity and harmonious of man and society in the process from the target conception to achievement, and then shapes engineering talents.

\section{Mechanism of Absorbing the Essence and Rejecting the Dross}

In the decade of the information highly developed, engineering education is facing the world changing rapidly, and all industries present the changing situation. Therefore, capturing the demand information of engineering talents at this stage and predicting the development trend of engineering science in the future is the ability that engineering education should master. It requires engineering education to establish its own information collection system and accurately search related knowledge and detailed information through the development trend of the industry. By way of knowing hiring needs and running the current situation, the teaching process can quickly adjust to the needs of the community. The thinking way and behavior pattern that are out of times should be carved or cut teaching proportion. The elites of the engineering education can be retained and redundancy parts that do not adapt to the educational demand can be cut.

\section{Conclusions}

The innovation of CDIO engineering education is a complicated process, which is influenced by many factors, such as society, school, and environment. Innovating engineering education by adopting CDIO mode is not just a fusion of these two systems, but also the co-adaptation of engineering education and the subsystems of CDIO mode. The innovation combined with CDIO mode on four basic stages of objectives' setting, planning and design, implementation process and feedback loop has improved the students' practical capability, spread their innovative thinking, and inspired their learning pattern. This paper puts forward four mechanisms of the CDIO engineering education including practice optimization, cross integration, ability and political integrity, and absorbing the essence and rejecting the dross.

\section{REFERENCES}

Wisuit Sunthonk and kpong. "Future Global Visions of Engineering Education,” Engineering Procedia, No.8, pp.160-164, 2011

Han Baozhi. "Constructing cultivating system of engineering innovative talents to speed engineering education reform,”. China Higher Education, No.10, pp.12-13, 2011

Poh-Hui Chua,Sin-Moh Cheah,Mark Nivan Singh. "Intergating CDIO Skills Into A Statistics Module,” 7th International CDIO Conference, pp.1-2, 2011

Wei Yi, Zhang Yuanming, Wan yi. "The Intertial Thinking Based on CDIO Mode of Engineering Education,” Journal of Modern Information, No.4, pp.112-113, 2011

$\mathrm{Hu}$ Zhigang, Ren Shengbing. "Program Optimization Based on CDIO-CMM for Undergraduate Education in Engineering," Research in Higher Education of Engineering, pp.20-21, 2010

Robert W. "The CDIO Syllabus And Outcomes-Based Assessment," 6th International CDIO Conference, pp.15-18, 2010

Yu Shouwen. "University,a place to Foster Talents," Research in Higher Education of Engineering, No.2, pp.12, 2011

Zhou Ling. "New Features and Developments of Engineering Education,” Tsinghua Journal of Education, vol.31, No.1, pp.115-117,2010

Jiang Shuyong. "Analysis of Orientation in Engineering Training Teaching in Terms of Functions of Higher Engineering Education,” Higher Education Forum,No.4, pp.71-73, 2010

Zhuang Qimin. "Design and Practice for Project Level One Based on CDIO Idea," Research in Higher Education of Engineering,No.6,pp.19-23,2008 